\title{
CONTRIBUTION OF MICROFINANCE IN ENHANCING FOOD ACCESS AND COPING STRATEGY IN AIDS-AFFECTED HOUSEHOLDS IN KAKAMEGA COUNTY, KENYA
}

$$
\text { Ngala } \mathrm{CO}^{1^{*}}, \text { Nguka }^{2} \text { and PO Ong'anyi }{ }^{3}
$$

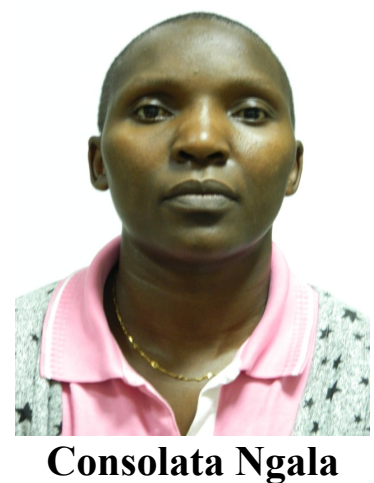

*Corresponding author: connieoloo@yahoo.co.uk

${ }^{1}$ Lecturer, Department of Economics, Masinde Muliro University of Science and Technology, Kakamega, Kenya

${ }^{2}$ Senior Lecturer, Department of Nutritional Sciences, Masinde Muliro University of Science and Technology, Kakamenga, Kenya

${ }^{3}$ Lecturer, Department of Social Sciences, Kibabii University College, Bungoma, Kenya 


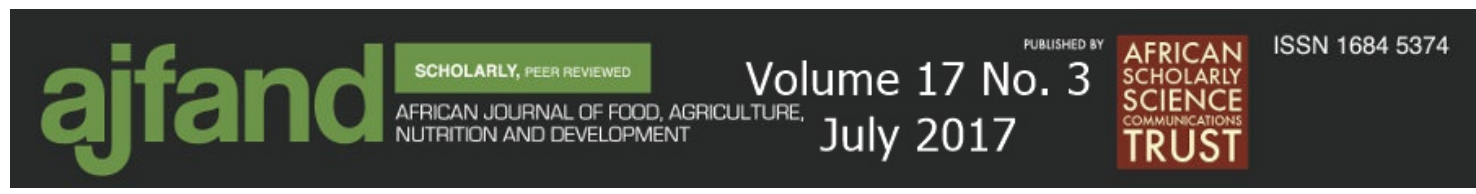

\begin{abstract}
Acquired immune deficiency syndrome (AIDS) pandemic increases a family's food insecurity by reducing the family's ability to produce food, which compromises their output and income. This reduces their food availability, accessibility and acquisition, and interferes with regular nutritional intake. In response, households develop various coping strategies, especially in the context of food shortages. Arguably, microfinance (MF) has been advocated by many as an antidote to disasters affecting the households in different disaster contexts, such as famine, poverty, and tsunami occurrences. This study, therefore, sought to find out the contribution of MF to AIDS-affected households in terms of food access and coping strategies in Kakamega County, Kenya. Specifically, the study determined the effect of MF on the proportion of income spent on food, and number of meals consumed in a day. It also sought to illuminate the coping strategies adopted by AIDS-affected households with and without MF in the context of food shortages. This study adopted both qualitative and quantitative approaches with an experimental framework. A sample of 404 AIDS-affected household heads was included in the study. Findings from descriptive and inferential analyses revealed that over $50 \%$ of AIDS-affected households before MF were spending their income on food irrespective of loan status, and there was a highly statistically significant difference in the proportion of income spent on food by affected households with and without MF. Those households with MF spent almost twice of their income on food compared to those without MF. There was also a highly statistically significant difference in the number of meals consumed between those households with and without MF, in favour of those with MF. Households with MF took relatively more meals. Lastly, households without MF adopted more severe coping strategies when faced with food shortages. The study concluded that affected households with MF had easy access to food, ate the required number of meals and adopted less severe coping strategies. This was because MF services came as a package of money, training and advisory on business and health-related issues, which did not only improve household income but also enhanced food access and enabled adoption of less severe coping strategies in AIDS-affected households in Kakamega County.
\end{abstract}

Key words: AIDS, Microfinance, Food, Security, Access, Affected, Non-affected, Coping strategy 


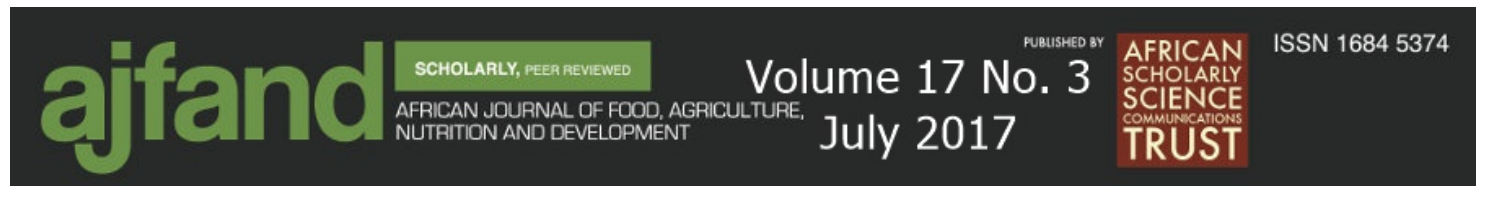

\section{INTRODUCTION}

Multiple anecdotes and empirical evidence have demonstrated that Acquired Immune Deficiency Syndrome (AIDS) affected households are likely to suffer from food insecurity $[1,2]$. Food security is a situation "when all people at all times have access to sufficient, safe, nutritious food to maintain a healthy and active life" [3]. The AIDS pandemic increases family's food insecurity by reducing the family's ability to produce food, which compromises their output and income. This, in turn, reduces their food availability, accessibility and acquisition, as well as interferes with regular nutritional intake. This makes households develop various coping strategies, especially in the context of food shortage.

Microfinance (MF), on the other hand, has been advocated by many as an antidote to disasters such as famine, poverty, tsunami occurrences, and AIDS [4, 5]. However, other studies $[6,7]$ have pointed out that microfinance products, especially loans, have driven people into a debt trap; microfinance has become a micro-debt that impoverishes rather than improves income of the affected poor households.

To better understand the link between access to MF and food security, studies done in Guatemala and Zambia found that new clients had higher coping strategy indexes than continuing clients with 4.3 versus 3.7 and 7.7 versus 4.7 , respectively, even though the differences were not statistically significant [8]. Coping strategy refers to ways that AIDS-affected households adapt to food shortages. Studies done in Guatemala and Zambia had their coping strategy indexes out of 10. High coping strategy index also means severe. These severe coping strategies are harsh ways of trying to survive without food. Example, when a household does not have food to an extent that they are forced to skip a meal. Everybody in the entire house including children and older persons goes without food. In a range of 0-10, 0-4 index would mean low coping strategy, 4-6 moderate and 6-10 high or severe coping strategy. High coping strategy is bad. It means that new clients both in Zambia and Guatemala were suffering from food insecurity and, therefore, adopted ways of dealing without food such as skipping meals because they lack what to eat. This wide range is seen in Zambia where new clients' coping strategy index was 7.7 and old clients' index was 4.7, a difference of 3 . Guatemala's case was not statistically significant since it was only a difference of 0.6 even though they belonged to different classes of severity (4.7 vs. 3.7). This means that new clients were more food insecure as compared to old clients of Microfinance.

A cross-sectional study in Nairobi, Kenya, compared clients of MF and non-MF and found that the two groups used different coping strategies when constrained financially to acquire food. Microfinance clients bought cheaper types of food while non-clients took food on credit from local vendors. In addition, both clients consumed street foods that were cheaper than supermarket foods. On patterns of consumption, two-thirds of MF clients reported that the pattern of a household's food consumption had not changed with the loan. This is because women with loans had exercised financial discipline in order to meet weekly repayments and compulsory savings. Therefore, they were left with little expendable income. On expenditure, the study found that households with MF spent significantly more on food than those without [9]. Another 


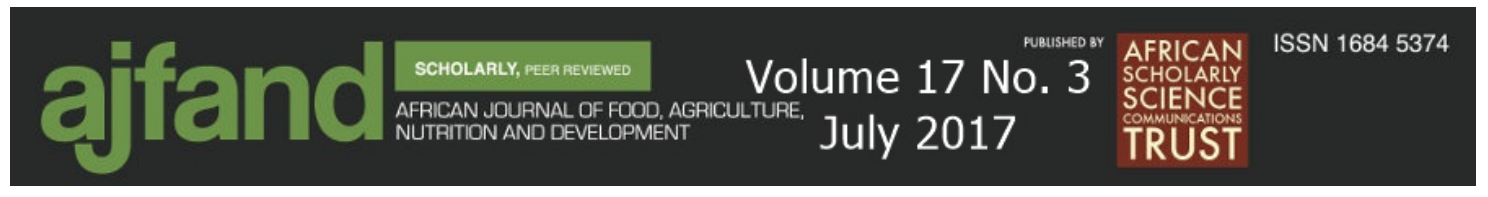

study pointed out that affected households developed different strategies to cope with AIDS and food shortages. Some of the strategies were: migrating in search of jobs, skipping meals, sending household members to eat elsewhere, limiting food portion size at mealtime, reducing number of meals eaten per day, relying on less expensive or less preferred food, purchasing or borrowing food on credit or relying on help from friends or relatives, gathering unusual type or amounts of wild foods, harvesting immature crops, sending household members to beg, reducing adult consumption so children can eat and relying on casual labour for food [10].

In Bangladesh, a study on ultra-poor households discovered that MF confers significant benefits in coping with seasonal famine. Both household members of MF who consumed between two to three meals a day and those that consumed between one to two meals a day saw their food security improve due to MF membership during the seasonal famine [11].

In Kenya, the World Bank prescribed the introduction of a security scheme that would be implemented by the government and local financial institutions to deal with the effect of AIDS on households [12]. This prescription was due to the negative impact that Human Immunodeficiency Virus (HIV) and AIDS had on food security in the early 2000's. The government responded by implementing an immediate priority to raise household incomes to combat the negative impact of AIDS on food security [13]. Kakamega County, among other counties, was then used as a pilot area for microfinance institution (MFI) operations because of the high poverty level of 59\% [14]. After the declaration of the year 2005 as a microcredit year, there was further influx of MFIs in Kakamega County. Since then, no research has been done to unravel the contribution of MF to AIDS-affected household food security and, therefore, a paucity of empirical research in this area exists.

This study, therefore, gathered information on the contribution of MF to AIDS-affected households. Specifically, this study sought to determine the effect of MF on the number of meals eaten in a day, percentage of income spent on food, and coping strategies in the context of food shortages in Kakamega County between AIDS-affected households with and without MF.

\section{METHODOLOGY}

\section{Study area description}

The study was carried out in Kakamega County of the former Western province of Kenya. The study area constitutes seven profiled sub-counties namely: Kakamega Central, Kakamega South, Kakamega East, Kakamega West, Mumias, Lugari, and Butere. Kakamega County covers $3,051 \mathrm{~km}^{2}$ and borders Bungoma County to the North, Busia County to the North West, Uasin Gishu County to the North East, Siaya County to the South West and Vihiga County to the South. The study area lies within latitude $0^{\circ} 15^{\prime}$ and $0^{\circ} 1 \mathrm{~N}$ and longitude $34^{\circ} 20^{\prime}$ and $35^{\circ} 00^{\prime \prime} \mathrm{E}$ (refer to Figure 1). It lies within altitude $1,250 \mathrm{~m}-2,000 \mathrm{~m}$ with the average annual rainfall ranging from 1250 $1750 \mathrm{~mm}$. The average temperature in the county is $22.5^{\circ} \mathrm{C}$ most of the year. Kakamega County has natural resources, such as gold, arable land and forests. The county's main 


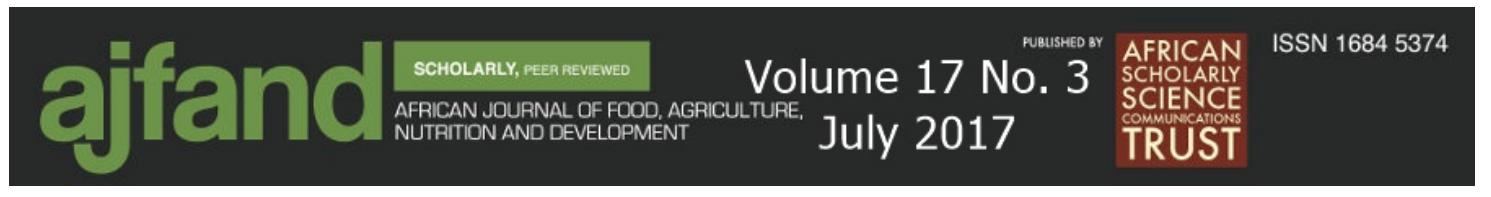

economic activities include large-scale sugarcane farming, mixed farming, commercial businesses, and bodaboda transport (motorcycle taxi) business, among others. However, despite all of these strengths, $57 \%$ of the population still live below the poverty line [15] and an HIV and AIDS prevalence of 5.6\% prevails [16].

This study was done in Kakamega County for several reasons. First, there is a lack of comparable studies and an almost absence of concrete information concerning MF and AIDS mitigation. Second, the study area continues to be one of the main rural population concentrations in Kenya with about 1,660,651 residents [17], a population growth rate of $2.5 \%$, and fertility rate of $5.6 \%$ greater than the national rate of $4.6 \%$ [16]. Third, Kakamega County has one of the highest population mobility due to several agro-based industries in the region. This high population mobility likely increases AIDS prevalence. These demographic and socio-economic factors are a key challenge for the county. Fourth, Kakamega County hosts a number of MFIs and nongovernmental organizations (NGOs). These MFIs are Kenya Rural Enterprise Bank (Krep Bank), Kenya Women Finance Trust (KWFT), Faulu Kenya, Western Development Cooperative (WEDCO), Small and Medium Enterprise Programmes Limited (SMEP), Ecumenical Loans Fund (ECLOF), Opportunity, Equity Bank, Rupia and Western Education Advocacy and Empowerment Program (WEAEP) [18]. The interaction of these MFIs and AIDS disaster mitigation in the County warrants serious investigation.

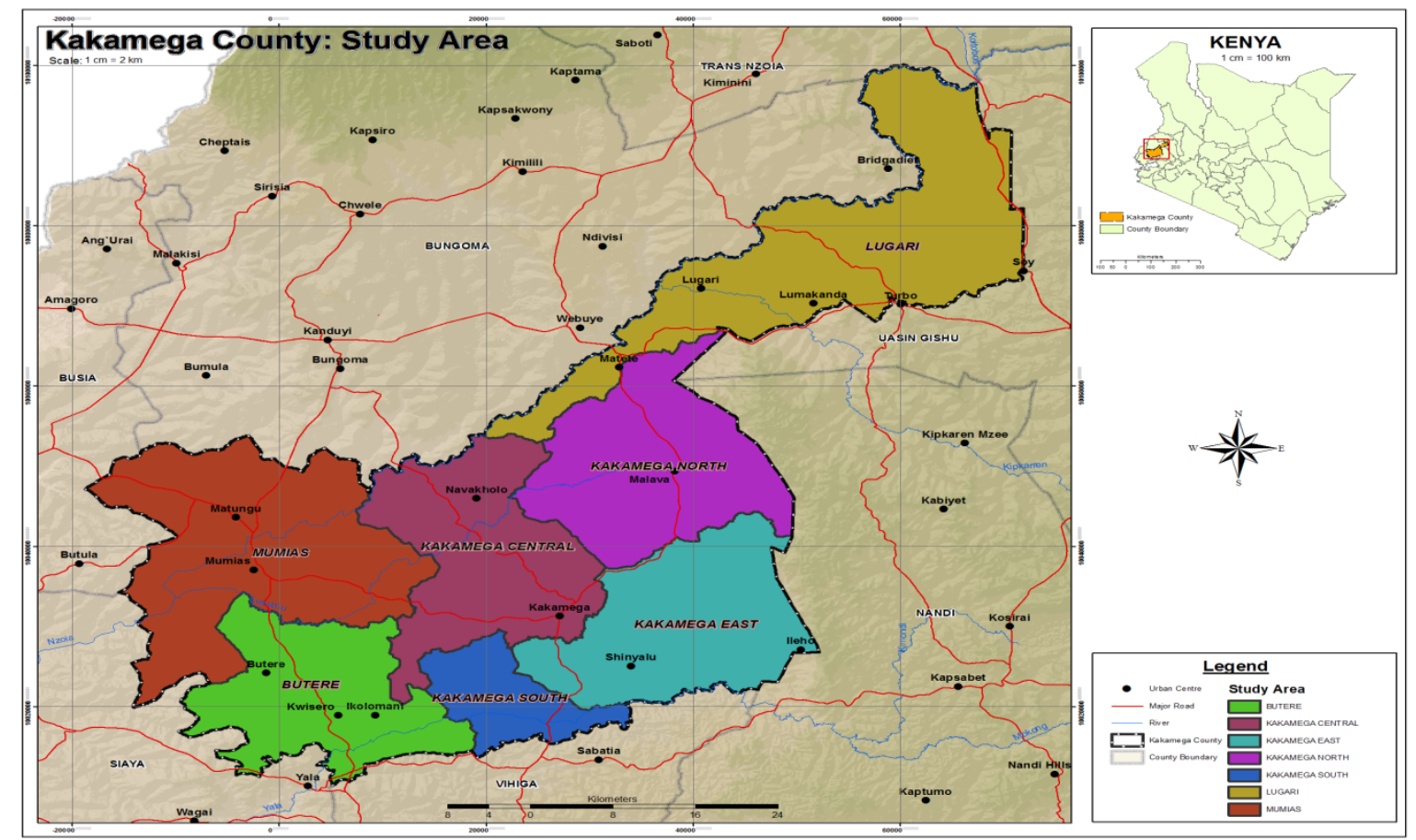

Figure 1: Map of Kakamega County depicting profiled sub-counties Source: Researchers, 2015

\section{Research design}

The study utilized experimental research design with both qualitative and quantitative approaches. These methods did not only provide an effective means of collecting high quality data but also served as a way to triangulate. Cross-sectional studies are 


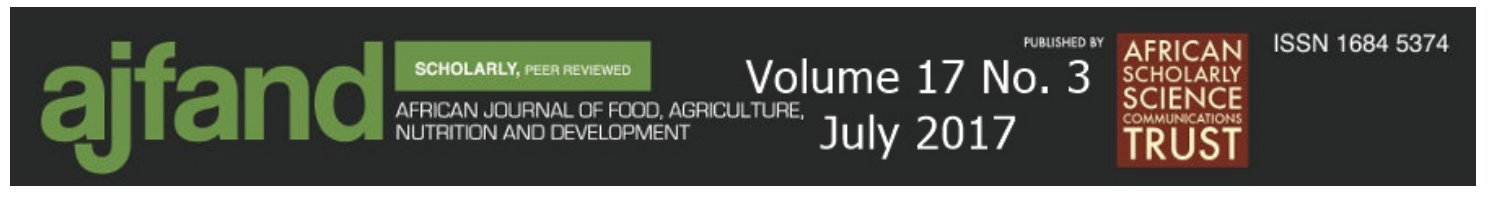

recommended for their robustness when it comes to studies on effects of relationships $[19,20]$. This study compared AIDS-affected household clients of MFIs either with MF (experimental group) and those without MF (control group). This was to ensure that the population under study was homogeneous to enable control of selection bias and isolation of external factors. Inherent characteristics, such as entrepreneurial drive and ability to move between the experimental group and the control groups, were controlled through selection of the MFI clients for both groups [21, 22].

\section{Sampling procedure}

The study adopted a variety of sampling methods to select the study site and sample respondents. Purposive sampling was used to select Kakamega County as the study area and AIDS-affected households. These households were then isolated into two strata. The first stratum was made of AIDS-affected household clients with MF while the second was comprised of AIDS-affected households who had applied for and were awaiting MF (without MF). Simple random sampling was then employed to select 202 respondents from the first stratum. On the other hand, purposive sampling was used to select households from the second stratum since not all affected households without MF had applied for MF. The researchers expected that the differences observed from these two strata would reveal the true influence of MF services to AIDS mitigation. A minimum sample size of 404 household respondents was used for the study. To get a representative sample of the affected households for each sub-county, samples of AIDS-affected households were picked proportionate to the number of households in each profiled sub-county.

Credit officers, programme managers and the coordinator, Pamoja Positive Voices Network, were also purposively selected for the study. Pamoja Positive Voices Network is an umbrella organization of AIDS support groups in Western Kenya region that was used to identify the groups. These support groups acted as an easy link to AIDS-affected households in the community that generated potential study respondents. The researchers interviewed all the MF credit officers and managers in the study area.

\section{Data collection and analyses}

This study used mainly primary data, which were collected by use of structured questionnaires, focus group discussions (FGDs) and in-depth interviews. Target respondents were household heads, credit officers and managers of MFIs. Descriptive analysis was done to distinguish the proportion of income spent on food and number of meals consumed per day between households with and without MF. Income in this case referred to the total amount of cash earned by households from the various economic activities that they engage. Furthermore, Mann-Whitney U test was applied to compare mean rank of expenditure on food with and without MF and also to compare mean rank of number of meals consumed by respondent with and without MF. These two main variables, that is proportion of income spent on food and number of meals consumed in a day, measured the food access component of food security.

Finally, content analysis was done to group the coping strategies into common themes based on severity. First, AIDS-affected household respondents were requested to 


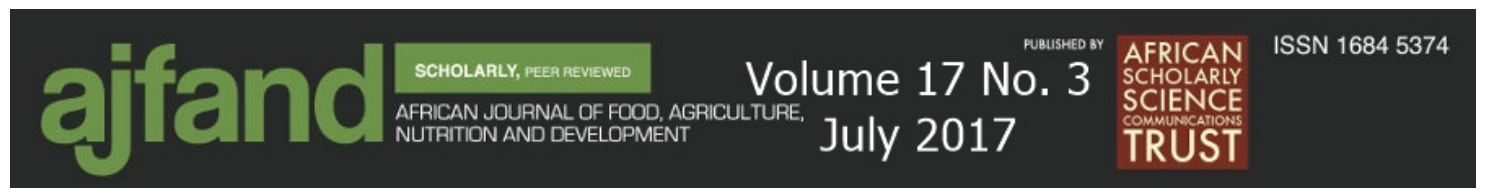

mention ways in which they cope without food. This gave out multiple responses. They were again later requested to group these responses into three categories: in terms of severity from high, moderate to low and severe. Descriptive analysis was done by derivation of percentages to show the most common coping strategy among respondents with and without MF in the context of food shortage. A coping strategy index was then developed for affected household respondents with and without MF services in Kakamega County.

\section{RESULTS}

\section{Proportion of household income spent on food as a measure of food access}

Table 1 shows that over $50 \%$ of the respondents reported spending their income on food irrespective of loan status. A significant number of households, $44.4 \%$ (91), with loan and $30.2 \%(60)$ without loan also reported that expenditure on education took the bulk of their income. Only $4.9 \%$ (10) with loan and 10\% (17) without loan indicated that expenditure on health took the bulk of their income.

The analysis of percentage of income spent on food, on the other hand, indicated that the majority, $52.9 \%$ (108), of affected households who spent between 31 and $50 \%$ of their income on food before loan were now spending between 51 and $70 \%$ of their income on food after the loan. A significant percentage, 19.2\% (39), also spent above $70 \%$ of their income on food; this they never did before MF services (see Table 2). The majority $[71.4 \%(142)]$ of households without MF, on average, spent between 31 and $70 \%$ of their income on food.

Mann Whitney U test showed that there was a highly statistical significant difference in percentage income spent on food by households with and without MF $(U=1189, p<$ 0.001 and $z=-13.431)$ Ref.? Those households with MF spent almost two times more (mean rank $=240.7$ ) of their income on food compared to those without MF (mean rank $=105.97)$. The $\mathrm{z}$ calculated value $(-13.431)$ when compared with the $\mathrm{z}$ critical value $( \pm 1.645)$ gave enough evidence to reject the null hypothesis (see Table 5).

\section{Number of meals as a measure of food access}

About $46.8 \%$ (96) of respondents with MF took three meals a day before MF services but after MF services the number rose to $70.7 \%$ (145). On the other hand, approximately $52.8 \%$ (105) of those households without MF took only two meals a day. Furthermore, results $(\mathrm{U}=1799, \mathrm{p}<0.001$ and $\mathrm{z}=-12.688)$ proved that there was a statistically significant difference between number of meals consumed by those households with and without MF. Moreover, households with MF took relatively more meals (Mean rank $=234.2$ ) than those without MF (mean rank $=109.04$ ) as shown in Table 5. The $\mathrm{z}$ calculated value of -12.688 when compared with the $\mathrm{z}$ critical value of \pm 1.645 gave enough evidence to reject the null hypothesis.

\section{Coping strategies}

When coping strategies in the context of food shortage were introduced to find out how AIDS-affected households dealt with the food shortage (referred to as Inzala, meaning any sort of food shortage irrespective of its severity in standard Luyha dialects). 


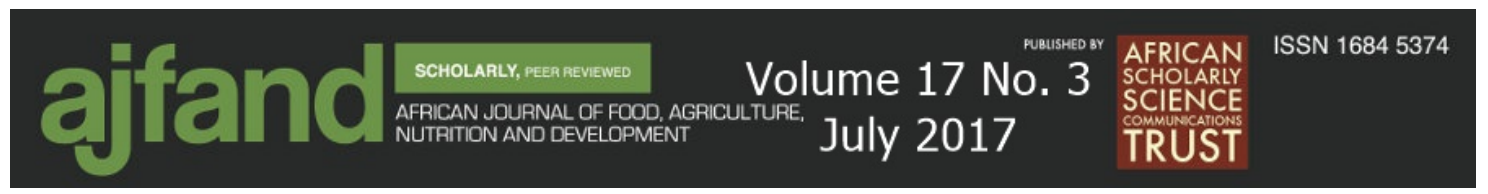

Irrespective of loan status, the majority, $38.5 \%$ (156), of households borrowed food from neighbours, relatives and friends and paid for it at a later date. Many, 27.3\% (110), skipped meals when they had no food. This was followed by working for someone $13.3 \%$ (54). In some circumstances, children $\{10.6 \%(43)\}$ were reportedly sent to go and eat at their relatives' (mainly grandparents' and uncles') houses. Eating less, this includes rationing food during some occasions and "topping up" with chewing sugarcane and drinking water, accounted for 10.1\% (41) as shown in Table 7. These strategies were grouped into three by AIDS-affected household respondents: severe, which comprised skipping meals (go without food), drinking water, sending children to eat at neighbours/ relatives (grandparents and uncles) and working for someone for food or money; moderate on the other hand, included rationing, eating less meals in a day and consuming wild fruits such as guavas when in season and wild vegetables during dry season (weeds); and low / normal coping strategies, which include borrowing from neighbours and purchase on credit to pay at a later date.

Based on the coping strategy groupings, a coping strategy index was developed as shown in Figure 2. Comparing households with and without MF, 39.5\% (81) of the households with MF had a less severe coping strategy. Only 18.6\% (37) of households without MF belonged to this category. However, the reverse was true of moderate and severe coping strategies as the greater majority of households without MF dominated at $43.8 \%$ (87) and 38.7\% (77), respectively. These findings revealed that households without MF were more food insecure.

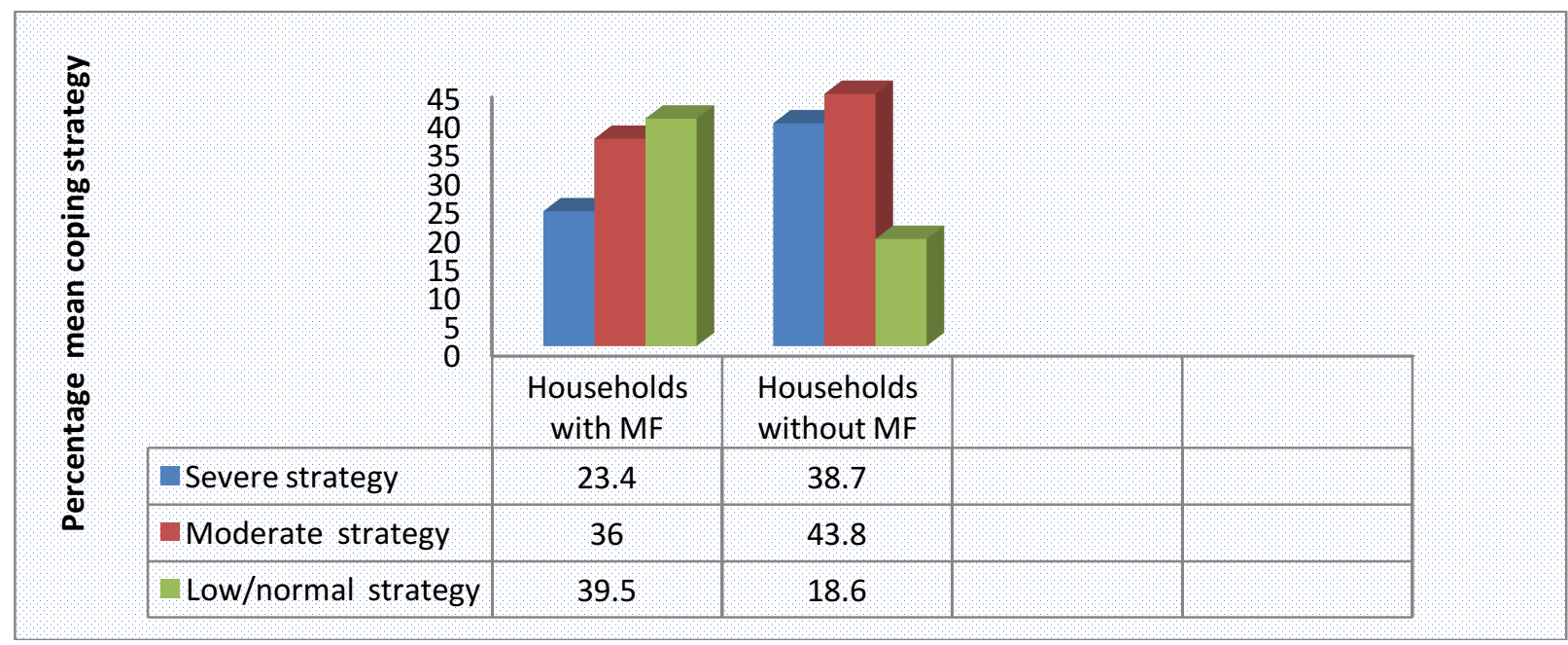

Figure 2: Coping strategy index by affected household respondents with and without MF in Kakamega County, Kenya

\section{DISCUSSION}

Statistics show that in Kakamega County, not less than $60 \%$ of people suffer from poverty [20]. This high poverty level would mean that poor households spend a greater portion of their income on food as the situation is exacerbated by AIDS vulnerability. This study also found that most AIDS-affected households in Kakamega County spend over $50 \%$ of their income on food. Notably, affected households with MF who reported that food formed the bulk of their expenditure had their expenditure on food increasing 


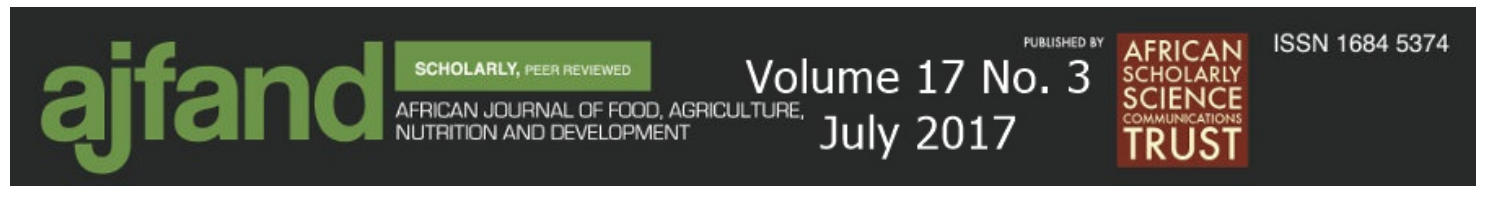

with MF services. From the study findings, microfinance facilities have been able to cushion those who have accessed it. Findings from one objective of this study revealed a strong correlation between MF access and income levels. This means that income earned by AIDS-affected households with MF had improved (changed positively) but those without MF remained as it were. Studies have shown that as income increases consumption also increases, although less proportionately $[9,10]$.

Second, the study sample comprised of poor AIDS-affected households and probably the reason for the demand for MF. Rich people do not go for microfinance; only the poor with a financial gap do. Most of these households take ARV's on daily basis, and they are also advised to eat well. This, perhaps, is one of the reasons why affected households with MF increased their expenditure on food as compared with AIDSaffected Households without MF.

This greater percentage of expenditure on food by those with and without MF could also have been caused by inflation. Economic Survey of 2013 indicated that consumer price index had been on the rise since the year 2010. It rose from $106.3 \%$ in 2010 to $121.2 \%$ in 2011 and further to $132.5 \%$ in 2012 , giving an annual percentage rate of change of $9.4 \%$ [15]. In the first quarter of 2013, oil prices were relatively higher and this together with the March $4^{\text {th }} 2013$ general elections in Kenya fueled prices even further in February 2013, a month to elections [15]. These could possibly justify why most of the affected households' expenditure on food rose irrespective of their loan status.

The rise in affected households' expenditure on food was also an indication that most Kakamega County AIDS-affected residents with MF probably do not produce enough food for their own consumption as they are largely engaged in businesses (Table 2). The respondents, therefore, filled the food gap by purchase of food, thereby increasing their expenditure on food after MF. This also meant that affected households had diverse sources of income after MF. Affected households alluded to engaging in various income activities such as Bodaboda (motorcycle), taxi, sale of paraffin, operating shops, construction of rooms for rentals, sale of greens and cereals (groceries). Therefore, incomes of affected households with MF increased with MF services, which meant more purchasing power. This confirms a study in Uganda that revealed that programme participation was strongly associated with specific types of diversification of income sources, thus multiplying ways of spreading the risk [23]. This increased the purchasing power of the affected households and made them rely on the market for food. It also agrees with a similar study done in Southern Sudan, which found out that food secure households rely much more on the market than the food insecure households [24].

This study revealed that the number of meals increased among AIDS-affected households with MF. This further increased households' proportion of income spent on food, an indication that MF improved food eating patterns of affected households. They can access food easily compared to their counterparts without MF. This study demonstrated a shift in agriculture to small scale business. One of the instructions (questions asked) in the study was "state your main source of income before and after MF". Responses to this question revealed that majority of affected households with MF 


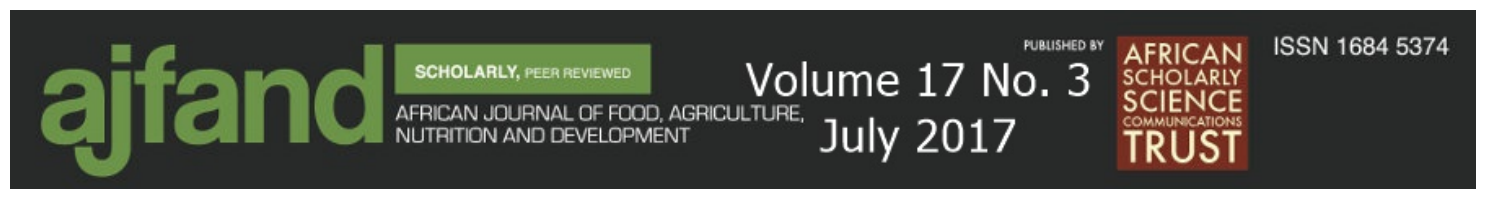

were in agriculture before MF. But, surprisingly, after MF majority of them stated business as the main source of income, 38.5\% (79) with MF versus $20.6 \%$ (41) without $\mathrm{MF}$, respectively. Microfinance enabled income source diversification, and, therefore, respondents with MF could have moved away from agriculture as their main source of income. They engaged in both agriculture and non-agricultural activities to diversify their source of income. The non-agricultural activity, however, becomes the alternative major source of income. Microfinance facilities range from small loans accompanied with training on business management, agricultural production and in health related issues. Income in this case is, therefore, any cash earned either before or after MF from economic activities that AIDS-affected households engaged in. Households affected with AIDS could have decided that after accessing MF they will further improve on their agricultural production, sell their agricultural produce to get cash income. It is this proportion of total cash income that was spent on food that the study captured. Income source diversification improved their liquidity status, which further made them to rely on market for food and, therefore, spending more on food. The improvement in the liquidity status of AIDS-affected households with MF was also vital as they had to pay monthly contributions towards the loan in cash. A study done in Pakistan by Kausar [25] pointed out that demand for loans is higher in those districts that are more agricultural and that as households get more loans, they tend to go for off- farm investments.

\section{Coping Strategy}

Food shortage could be a major risk to HIV infection. A study in Haiti maintains that inadequate income can be the reason why people accept payment for sexual favours. Inadequate income could lead to increased risk of exposure to HIV infection [26] while those in South Africa [27] and Rome found out that food insecurity and malnutrition may increase susceptibility to HIV as well as vulnerability to AIDS impacts [28].

Content analysis of affected households' responses from FGDs revealed different levels of severity in food shortage, given adopted coping strategies by AIDS-affected households. Most households with MF adopted more of less severe coping strategies, while affected households without MF adopted more of severe coping strategies (see Figure 2). These findings concur with those in Zambia and Guatemala that revealed that new clients of MF had a higher (more severe) coping strategy index than old clients of MF [8].

\section{CONCLUSION}

It is evident, therefore, that MF increases food access and reduces severity of coping strategies in the context of food shortages experienced by AIDS-affected households. The overall performance of AIDS-affected households with MF services was quite encouraging. This, then, provides a basis for recommending the use of microfinance services as an intervention that not only improves the quality of life among AIDSaffected households but also complements other therapeutic measures to improve the health of both the infected and the affected (non-affected household members of an infected individual) persons. 


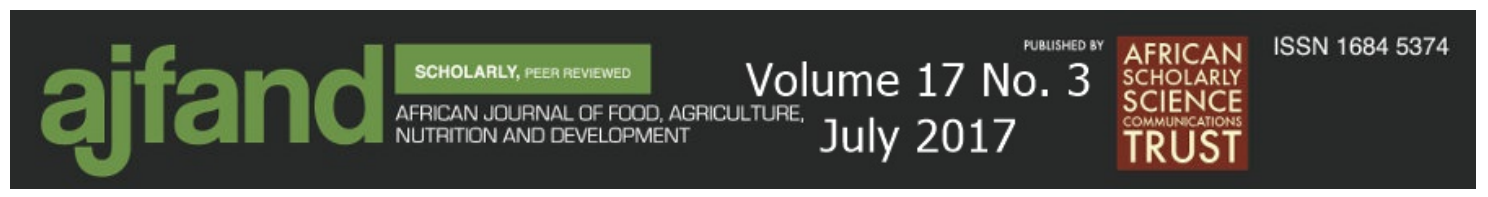

Table1: Percentage distribution of expenditure items that take the bulk of household's income with and without Microfinance

\begin{tabular}{lccr} 
Sample size $=\mathbf{4 0 4}$ & & & \\
Item & With Microfinance & Without Microfinance & Pooled \\
\hline Food & 50.7 & 59.8 & 66.3 \\
Education & 44.4 & 30.2 & 31.2 \\
Health & 4.9 & 10.0 & 2.5 \\
\hline & & & 100 \\
\hline
\end{tabular}

Source: Researchers, 2015

Table 2: Percentage distribution of expenditure on food before and after Microfinance by respondents with Microfinance

Sample size $=\mathbf{2 0 2}$

Monthly expenditure

Before Microfinance

After Microfinance

\begin{tabular}{lcc}
\hline Below $30 \%$ & 56.7 & - \\
$31-50 \%$ & 22.1 & 27.9 \\
& & 52.9 \\
$50-70 \%$ & 12.5 & 19.2 \\
Above $70 \%$ & 8.7 & \\
& & 100
\end{tabular}

Source: Researchers, 2015

Table 3: Percentage distribution of income by respondents with Microfinance, without Microfinance and pooled estimate

Sample size $=\mathbf{4 0 4}$

\begin{tabular}{lccr}
\hline Current Monthly Income & With Microfinance & Without Microfinance & Pooled \\
& & & 56.8 \\
\hline Below Ksh 5,000 & 47.3 & 66.3 & 24.5 \\
Ksh 5001-10,000 & 27.8 & 21.1 & 14.3 \\
Ksh 10,001-20,000 & 19.0 & 9.6 & 4.4 \\
Above Ksh 20,000 & 5.9 & 3.0 & 100 \\
\hline Total & 100 & 100 &
\end{tabular}

Source: Researchers, 2015 


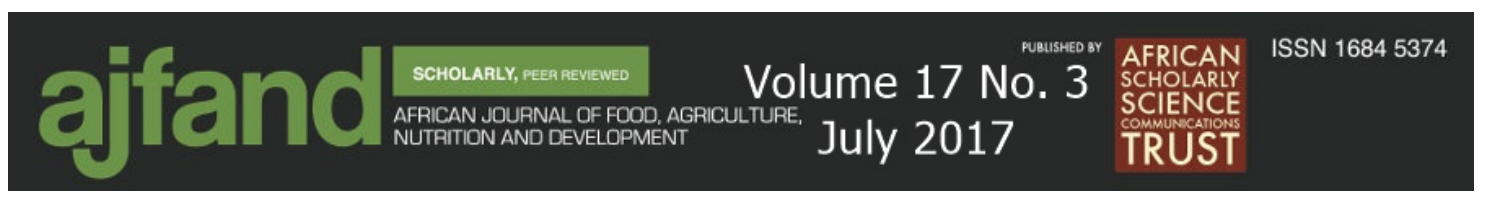

Table 4: Percentage distribution of source of income by household respondents with Microfinance, without Microfinance and pooled estimate

Sample size $=404$

\begin{tabular}{|c|c|c|c|}
\hline Source of Income & With Microfinance & Without Microfinance & Pooled \\
\hline Formal employment & 11.7 & 9.0 & 10.4 \\
\hline Business & 38.5 & 20.6 & 29.7 \\
\hline Agriculture & 43.5 & 55.8 & 49.5 \\
\hline Other & 6.3 & 14.6 & 10.4 \\
\hline Total & 100 & 100 & \\
\hline
\end{tabular}

Source: Researchers, 2015

Table 5: Comparison of mean income expenditure on food and mean number of meals for AIDS- Affected households with and without Microfinance

Sample size $=\mathbf{4 0 4}$

$\begin{array}{ll}\text { Percentage income } & \text { Number of meals taken by } \\ \text { expenditure on food for } & \text { households with and without } \\ \text { households with and } & \text { Microfinance }\end{array}$

without Microfinance

Mean rank households with

240.7

234.2

Microfinance

105.97

109.04

without Microfinance

Mann-Whitney U test

1189.00

1799.00

Wilcoxon W

21089.00

21699.00

$Z$ value

$-13.431$

$-12.688$

Sig (2-tailed)

0.000

0.000

Verdict

Reject Ho:

Reject Ho:

Highly Statistically significant

Highly Statistically significant 


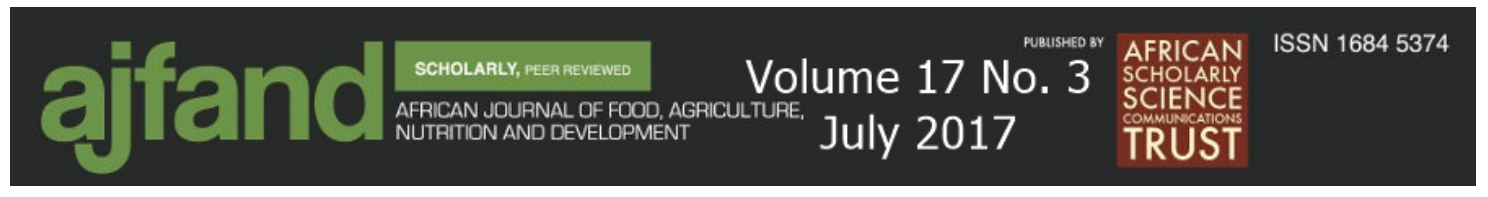

Table 6: Percentage of responses with coping strategies in the context of food shortages by AIDS-affected households' respondents with and without Microfinance

Sample size $=404$

Severe

Skipped meals

Eating from relatives houses or neighbours

Moderate

Borrowed food

Rationing/eating less and chewing sugar cane

Low/Normal

Working for someone for food or money

Never gone without meal

\section{Percentage responses}

27.3

10.6

38.5

10.1

13.3

0.2

Source: Researchers, 2015

Table 7: Percentage pooled estimate of coping strategies by AIDS-affected households' respondents with and without Microfinance

Sample size $=\mathbf{4 0 4}$

Coping Strategy

Pooled Estimate

Borrowed food from neighbour, relatives and friends

38.5

and paid at a later date

Skipped meals when had no food

Worked for someone

Sent children to go and eat from relatives

(grandparents and uncles)

Ate less (rationing and topping up with chewing sugar

cane or drinking water)

Never gone without meal

0.7

Total 100

Source: Researchers, 2015

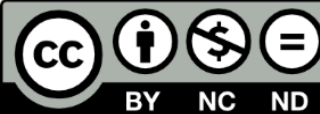




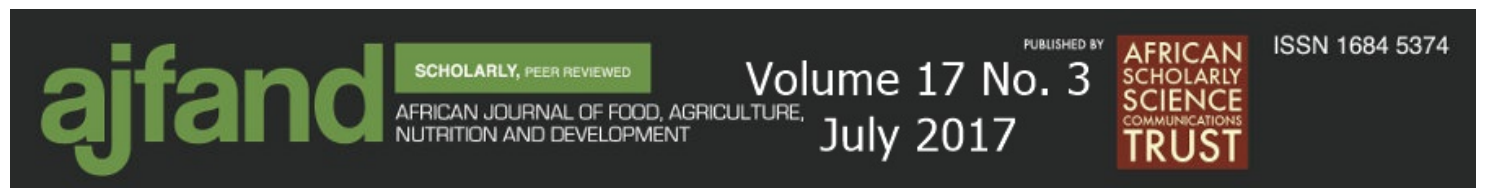

\section{REFERENCES}

1. Gillespie S and S Kidiyala HIV/AIDS and Food and Nutrition Security: From Evidence to action. In: Food Policy Review No.7.International Food Policy Research Institute (IFPRI). Washington DC, USA.2005.

2. Masuku MB and MM Sithole The impact of AIDS on food security and household vulnerability in Swaziland. Agrekon, 2009; Vol 48, No 2.

3. Food and Agricultural Organization. Rome Declaration on World Food Security and World Food Summit Plan of Action. Rome.1996.

4. Swaan K, Jacqueline B, Maylin M, Maxwell M and B Joske Promoting Food Security and well-being among poor and HIV/AIDS-affected households: Lessons from an interactive and integrated approach; Evaluation and Programme Planning; 2009;32(1): 31-42. Elsevier LTD.

5. Nanoor MA Microeconomic and its impact on selected districts in Eastern Region of Ghana. Kwame Nkuruma University. 2008.

6. Hulme D What's wrong and right with microfinance -missing an angle on responsible finance. The University of Manchester. 2009.

7. Morduch $\mathbf{J}$ The impact of microcredit on the poor in Bangladesh: Revisiting the evidence. Washington DC: Centre for Global Development, Working Paper \#174. 2009.

8. Paul H Exploring the linkage between food security and microfinance: A study by FINCA in Zambia and Guatemala. Field brief no. 11. FINCA International. 2012.

9. Bishop C, Kate G, Kristin W, Shannon S, Natalie $\mathbf{K}$ and P Paul Nutrition and food security for people living with HIV and AIDS. Catholic Relief Services. Baltimore, MD. 2006.

10. Thuita FM, Mwadume KN and JK Wang'ombe Influence of access to microfinance credit by women on households food consumption patterns in an urban low income setting in Nairobi, Kenya. European International Journal of Science and Technology 2013; 2(3): 2304-9693.

11. Claudia NB Impact of microfinance on food security, informal credit, and agricultural wages: The case of Bangladesh. UMI Dissertation Publishing.No.3609079.ProQuest LLC. 2014.

12. World Bank. Flood Development Report: Oxford University Press, Oxford. 2000 . 


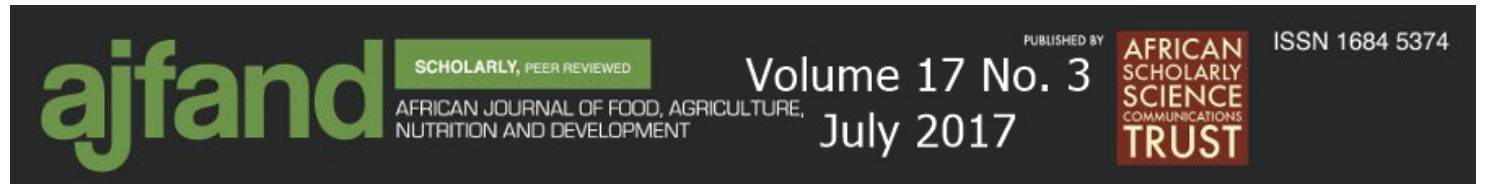

13. Republic of Kenya. HIV/AIDS in Kenya. Impact of the Epidemic. National AIDS Control Council. 2000.

14. Republic of Kenya. Kenya Welfare Monitoring Survey: Second report on poverty in Kenya. Incidence and depth of poverty. Volume 1. Central Bureau of Statistics. 1997.

15. Kenya National Bureau of Statistics. Kenya Economic Survey. Ministry of State Planning National Development Plan. Nairobi, Kenya. 2013.

16. United Nations Agency on Aids (UNAIDS). AIDS by the Numbers. 2013.

17. Kenya National Bureau of Statistics (KNBS) and ICF Macro. Kenya Demographic and Health Survey 2008-2009. Calverton, Maryland: KNBS and ICF. 2010.

18. Association of Microfinance Institutions (AMFI), Annual Report on the Microfinance sector in Kenya. Nairobi, Kenya.2012. www.naimax.com (accessed on 22/05/2014).

19. Ramani G and V Kumar Interaction Orientation and Firm Performance. Journal of Marketing. 2008; 72: 27-45.

20. O'Sullivan D and VA Abela Marketing performance, measurement ability and firm performance. Journal of Marketing. 2007; 71P:79-93.

21. Kim JC, Watts C, Hargreaves JR, Ndhlovu LX, Phetla G and LA Morison Understanding the impact of microfinance based intervention on women's empowerment and the reduction of intimate partner violence in South Africa. American Journal of Public Health 2007; 97(10): 1794-1802.

22. Czura K An impact assessment of microfinance in Sri-lanka-a household survey of microfinance clients in 5 selected GTZ partner Microfinance, Geoth University, Frankfurt.2010.

23. Barnes $\mathbf{C}$, Keogh $\mathbf{E}$, Nemarundwe $\mathbf{N}$ and $\mathbf{L}$ Nyikahandzoi Microfinance and mitigation of the impact of HIV/AIDS: An exploratory study. Management Systems International. University of Zimbabwe Horizons Program. 2002.

24. Nguka G and S Odebero The Crisis of Acute Malnutrition among Children in Southern Sudan. Causes, Prevalence Rates and Effectiveness in Clinical Management. Lambert Academic Publishing. 2011.

25. Kausar A Factors affect Microcredits: Demand in Pakistan: International Journal of Academic Research in Accounting, Finance and Management Science. 2013; 3 (4):11-17 ISSN 2225-8329. 


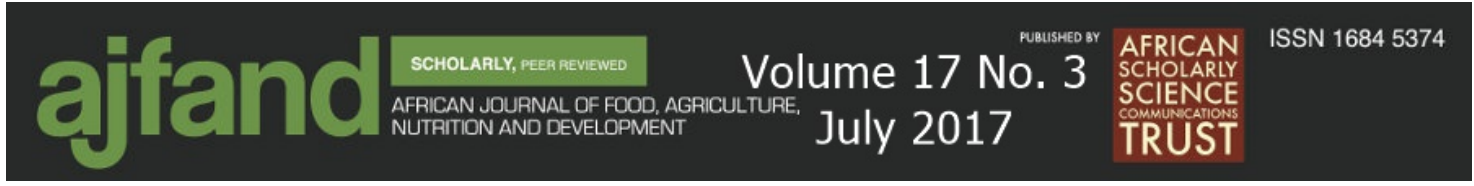

26. Longuet C, Machmon JM, Deschamps MM, Sincov R, Brignoli E, Pape JW and B Minibel Access to Microcredit for Women living with or Vulnerable to HIV in Haiti. Field Actions Sci Rep, 2009; 2: 85-91.

27. De Waal A and A Whitehead New Variant Famine: AIDS and Food Crisis in South Africa. The Lancet, 2003; 362: 1234-1237.

28. FAO. Food and Agriculture Organization. Food Security and HIV/AIDS. An Update Committee on World Food Security, 29 ${ }^{\text {th }}$ session 12-16 May 2003, Rome. 